\title{
Complementary and Alternative Medicine - Herbals and Supplements: A Review for the Primary Care Physician
}

\author{
Surya Davuluri $^{1}$, T. S. Dharmarajan ${ }^{2}$ \\ 1. Geriatrics, Albert Einstein College of Medicine 2. Montefiore Medical Center, Albert Einstein College \\ of Medicine
}

$\square$ Corresponding author: Surya Davuluri, suryakirandavuluri@gmail.com Disclosures can be found in Additional Information at the end of the article

\section{Abstract}

The pursuit of well-being coupled with perceived beliefs, suggested benefits, and myths have led to the widespread use of Complementary and Alternative Medicine (CAM). The terms Complementary and Alternative Medicine are often used interchangeably, although differences exist. The health care expenditure involving the use of CAM is estimated to be in the billions of dollars. Evidence-based medicine is the foundation of today's conventional (or allopathic) medicine. If the same principles of allopathic medicine can be extrapolated to CAM, one could more comfortably promote the use of CAM for the overall betterment of health and well-being and hopefully a favorable impact on health care. With the growing use of CAM by adults worldwide, providers must become informed and be able to discuss some of the potential benefits and harms, as well as possible interactions between CAM and conventional therapy. A discussion is included on nuts, caffeine, and alcohol, in addition to the use and misuse of vitamins.

\section{Categories: Internal Medicine}

Keywords: complementary medicine, alternative medicine, conventional therapy, herbals, supplements, herb-drug interactions

\section{Introduction And Background}

The terms "complementary medicine" and "alternative medicine" are commonly used and may denote different meaning to each person [1]. While the terms "complementary" and "alternative" are often used interchangeably, differences do exist, although some tend to even use two terms synonymously with traditional medicine. "Complementary" refers to a nonmainstream approach alongside conventional medicine, while "alternative" refers to a nonmainstream approach in place of conventional medicine [1]. Additional terms include "integrative" and "unconventional" medicine [2]. Substantial overlap may exist between conventional medicine and the other forms. Conventional medicine believes that health refers to an absence of disease, which is an alteration in organ or tissue structure, and alternative medicine believes in health resulting from a balance of opposing forces [3]. Accordingly, in lay terms, conventional medicine appears to suppress forces that make one ill while alternative therapy may strengthen health-promoting forces [3]. In this review, the preferred terms used will be "complementary medicine" and "alternative medicine" (CAM).

The broad umbrella of CAM includes herbal therapy (including numerous plant species), dietary supplements, and vitamins, in addition to other approaches. The additional modalities are numerous, including but not limited to: prayer, meditation, yoga, relaxation therapy, massage 
therapy, acupuncture, homeopathy, light therapy, transcutaneous electrical therapy, and biofeedback, for example. This review will focus on herbs and dietary supplements.

The term "Natural Products" includes herbs (or botanicals), minerals, and vitamins, marketed usually as dietary supplements [1]. A dietary or nutritional supplement is a dietary component that may cause certain manifestations when not consumed in adequate amounts, and broadly includes minerals, vitamins, amino acids, fatty acids, and fiber [4]. Dietary supplements are marketed in liquid, powder, bars, tablet, and capsule forms. Administration of supplements usually does not help make a diagnosis or provide a cure for disease, although such claims may be made in labeling; on the other hand, their excessive use can result in adverse or unwanted effects. Herbal supplement regulation is not under the control of the United States Food and Drug Administration (FDA).

The question often asked, for which a distinct answer is solicited, is: does CAM work? And further, is there evidence that CAM works? While past evidence is weak, it is clearer that in the present era, efforts are directed to verify and evaluate claims regarding benefits of CAM. The use of CAM has been on the rise in the past two decades. From about one-third of the population in the U.S. using CAM in the early 1990's, the number has risen to about one-half the population [2-3]. The pattern is quite similar in France, Netherlands, and the United Kingdom, with many general practitioners referring patients for some form of CAM therapy [3].

Prior to 1994, the regulatory category for dietary supplements included vitamins and minerals. The Dietary Supplement Health and Education Act (DSHEA) introduced in 1994 elaborated the list to include botanicals and other traditional medicinal products, excluding them from regulation by the FDA. But the Act did not subject supplements to the same safety precautions that apply to prescription and over-the-counter medications; it designated that supplements be regulated like foods, exempting manufacturers from conducting premarketing safety and efficacy tests [5]. Consequently, manufacturers are not required to provide premarketing safety or efficacy data [6]. The FDA believes that adverse events are markedly under-reported. Further, there are claims that dietary supplements may be contaminated with harmful ingredients or adulterated, with substantial possibility for harm [6]. Sometimes, claims for benefits during marketing are based on sound data while at other times they may be exaggerated [7]. There is a need for more effective regulation along with consumer and provider education, as physicians are poorly informed about the topic [6]. CAM being a multi-billion dollar industry, a lot is at stake for the industry, provider, and consumer.

More recently, the FDA has observed that dietary supplements may contain ingredients that have the potential for harm. Such a dietary ingredient may be a vitamin, mineral, herb, amino acid, or a metabolite [8]. Recalls of dietary supplements containing inappropriate ingredients have begun increasing, with efforts aimed at protecting the health and safety of the public [8]. Given their widespread use without good evidence, and the potential harm from food supplements, the policy of marketing these products without clinical evidence may require reconsideration [9].

Over the past decades, there has been a dramatic rise in the use of herbal products around the world, with these products classified and promoted as food rather than as pharmaceuticals [10]. In view of alterations in physiological function with aging, especially relating to renal and hepatic function, in addition to altered water and fat stores, older adults are particularly vulnerable to the effects of herbals [10]. Herbals and supplements are commonly used by the educated and high average income group, but importantly, the patient often does not disclose their use to the primary care providers [11]. However, in the European Union, the manufacturing and trade of herbs and dietary supplements are regulated by pharmaceutical and food laws [12]. In a survey of over 3,000 community individuals, where the majority was on 
prescription medications, $46 \%$ used over-the-counter medications and $52 \%$ also used dietary supplements, with the highest prevalence in the oldest age group [13]. Nearly half the patients were on anticoagulants; in these individuals, the potential for drug interactions require emphasis [13]. While claims made on the benefits of herbals and supplements may be assuring, scientific evidence is generally lacking and warrant further research.

\section{Review}

\section{Patterns and rationale for use of dietary supplements}

Data from the National Health Interview Survey reveals that a third of American women used CAM in the past 12 months; spiritual healing, prayer, and herbal medicine were the most commonly used. The women were more likely to be older, educated, white, and poorer in health, with insurance status not an independent association [14]. A report based on over 31,000 adults in the U.S aged 18 or older revealed the following: $62 \%$ used some form of CAM therapy during the prior 12 months; the most common were prayer, natural products, breathing exercise, meditation, yoga, and diet-based therapies; and the most utilized natural products were echinacea, ginseng, ginkgo biloba, and garlic [15]. The highest cited reasons for CAM use were the presence of back or neck pain, joint stiffness, and anxiety or depression [15]. Use varied with sex (more in women), race, health insurance status, geographical region, and the use of cigarettes or alcohol [15]. Attributed reasons for use included: CAM would work with conventional medicine, would be interesting, trial suggested by medical professionals, and that conventional medicine was too expensive [15].

Interestingly, adults on the U.S. side of the border with Mexico appeared to consume more herbs and nutritional supplements than their Mexican counterparts [16]. Some use herbals in addition to therapies prescribed by physicians. Nearly half the patients in a center for endocrinology and metabolic disorders self-medicated with dietary supplements without fear of side-effects from co-morbidity or other prescribed drugs [17]. Those with chronic conditions on herbals and dietary supplements are also unlikely to disclose use of these products, raising safety concerns [18]. Adults use supplements to treat or cure cognitive disorders more than to prevent them, with fish oil, ginkgo biloba, and vitamins most utilized [19-20]. Cancer-related anorexia and cachexia are another area where herbal medicine is used [21]. Nutraceuticals derived from herbs and food products are used in osteoarthritis when traditional drugs are contraindicated [22].

We should recognize that several dietary supplements are potentially harmful in patients with chronic kidney disease; providers should recognize and discuss these consequences with the patient [23]. Several herbals are associated with a spectrum of hepatotoxicity, too diverse to merit discussion here; all the same, there needs caution in interpretation of abnormal hepatic function, with a need to search for alternate causes beyond a herb or supplement [24-25]. The spiraling cost of allopathic treatments and some distrust with modern technology are additional reasons for people to turn to CAM [2]. The aforementioned statements suggest that when traditional medications are of no avail, the patient is likely to turn to any product that may be even remotely perceived to provide hope. While some see CAM as an approach for a cure without adverse effects, others may see the approach as a last resort for chronic illness. The 2007-2010 NHANES studied nearly 12,000 adults over age 20 years for reasons to use CAM. The common reasons were: improvement of health, maintenance of general health, bone health, and heart health and lowering cholesterol; older adults tended to be site specific, such as benefits for the heart, bones, or joints [26]. Less than a quarter of the adults took the product following the recommendation of a health provider; the users reported good health, had health insurance, and adhered to good lifestyle measures [26].

\section{Commonly used herbs in the United States}




\section{Echinacea}

Echinacea is commonly used for upper respiratory tract infections. Objective, well-controlled study data on its efficacy are lacking. Benefits are claimed for the immunological effects of echinacea extracts and its species, including a lower likelihood of catching a common cold and a shorter duration of the cold. Claims have been made regarding the immunological effects of echinacea in the prevention of cancer which the current scientific evidence does not back up. Use beyond 10 days is not recommended. Drug interactions occur with simvastatin, lansoprazole, and losartan, with the resultant increase in the drug levels [27-28].

\section{Ginseng}

Ginseng is used for improving cognitive and physical performance. The root is said to have stimulant or aphrodisiac effects and is considered helpful for sexual dysfunction, immunemodulatory effects, and enhancement of physical and cognitive performance. Scientific evidence is inconclusive based on systematic reviews of several randomized controlled trials published [29]. Ginseng is commonly involved in drug interactions; it interacts variably with warfarin, but largely blunts its action, increasing the tendency to thrombosis [30].

\section{Ginkgo Biloba}

Ginkgo biloba is used for the prevention or amelioration of dementia and as a memory enhancer, perhaps from its effect on inhibiting norepinephrine uptake. The herb has attracted attention as an agent that may help prevent Alzheimer's dementia; however, studies have not substantiated its efficacy. In a randomized controlled trial, a dose of $120 \mathrm{mg}$ twice a day of ginkgo biloba extract did not reduce the incidence of Alzheimer's dementia nor all-cause dementia [31]. Drug interactions include increasing the levels of acetaminophen, aspirin, and the anticoagulant effects of warfarin [30, 32-36].

\section{Garlic}

Garlic, otherwise known as Allium sativum, is a species of the onion genus and used commonly as a flavoring agent, taste enhancer, and seasoning agent. While garlic is largely fundamentally used for flavor and taste, it has also earned a reputation as a health-promoting agent for hypercholesterolemia. Onions, leeks, and chives are related species. The nutritional value comes from the fact that garlic not only contains vitamins and minerals, but in randomized controlled trials, data demonstrated a lower total cholesterol and triglyceride levels in those on garlic compared to placebo. Other alleged properties include beneficial effects in diabetes management and in preventing infections. The main side effect includes bad breath (halitosis) and pungent sweat attributed to a sulfide derived from garlic metabolism. Garlic reduces platelet aggregation and can increase bleeding tendency of aspirin or warfarin [30, 37-39].

\section{St. John's Wort}

St. John's wort is used widely for depression. Evidence indicates the herb may be effective in moderate depression as substantiated by meta-analysis and Cochrane database reviews. However, the herb is also associated with numerous drug-drug interactions through interaction with the cytochrome P450 system, resultant higher clearance of drugs and lower therapeutic efficacy; drugs affected include warfarin, statins, and calcium channel blockers. The effects of St. John's wort may relate to the inhibition of reuptake of neurotransmitters. The herb may contribute to the Serotonin Syndrome through interaction with drugs that elevate 5HT (serotonin) in the nervous system [40-42]. 


\section{Peppermint}

Peppermint is used for a variety of medicinal uses, predominantly gastrointestinal complaints, such as nausea, indigestion, irritable bowel syndrome, and abdominal pain. It is a flavoring agent used in candy, ice cream, tea, toothpaste, and other items, largely due its potent smell and taste properties attributable to menthol. Scientific evidence for benefits is inconclusive [43].

Ginger

Ginger or ginger root is used worldwide as a delicacy or spice. Related herbs are cardamom and turmeric. Known for its strong fragrance, ginger is used as a flavoring agent and for its perceived benefits for gastrointestinal discomfort, including nausea, indigestion, and numerous other manifestations. Ginger contains a variety of vitamins, especially the B group, besides minerals. Ginger does interact with serotonin receptors and prostaglandins to influence gastrointestinal function, the basis for use in a variety of abdominal manifestations. It also stimulates saliva production, rendering mastication easier. The FDA considers use in small amounts safe. Ginger interacts with warfarin, increasing its potency. Ginger may cause adverse effects in those with biliary tract disease [44].

\section{Soy}

Soy is used commonly in the United States and worldwide. Known as soybean or soya bean, it is a legume with an edible bean that can be used for multiple purposes. Derivatives include soy milk, soy sauce, tofu, bean paste, vegetable oil, and others. It is a good source of vegetable protein; in addition, soy contains polyunsaturated and monounsaturated fat, vitamins (mostly B type), and minerals, besides reasonable fiber content. Soy is a good meat and dairy substitute and comes in handy during nutritional recommendations. Soy contains isoflavones, a source of phytoestrogen, which has been used for menopausal symptoms. Long-term use and estrogenrelated effects are not clear. Soy has been recognized by the FDA for its cholesterol-lowering properties [45].

\section{Chamomile}

Chamomile is a beautiful daisy-like plant used for a variety of purposes. These include the promotion of sleep, as well as antiseptic and anti-inflammatory effects. The herb is said to influence gastrointestinal function by reducing gastric pepsin secretion. Neuroendocrine properties have been attributed to chamomile. The plant's emollient effects are used for cosmetic benefits involving the skin and hair [46-48].

\section{Kava Kava}

Kava (or kava kava) is used as a sedating agent and for the purpose of relaxation, often in social settings or events. Kava is taken as a drink or chewed, and has a distinct flavor. Kava use is often combined with alcohol consumption. The herbal ingredients have psychoactive properties with anxiolytic and cognitive effects similar to benzodiazepines. The properties have led to kava use linked to potential for addiction. Heavy use is followed by hepatotoxicity, renal dysfunction, and hematological effects, such as macrocytosis and impaired platelet function. The potential for drug interactions exists, especially with medications that have central nervous system effects [49-50].

Saw Palmetto 
Benign prostate hyperplasia (BPH) is common in older adults and tends to affect the quality of life in the elderly. Saw palmetto, especially in extract form, is often used by elderly men for the lower urinary tract manifestations of $\mathrm{BPH}$. Often, the primary physician is aware of the patient using saw palmetto along with other prescribed medications. Although tolerated, a beneficial effect is yet to be demonstrated consistently in randomized controlled trials [51].

Rhabdomyolysis, likely induced by saw palmetto, has been reported [52-53]. While the benefits of saw palmetto for manifestations of BPH are yet to be confirmed, there has been no demonstrable association between saw palmetto use and prostate cancer risk [54]. Drug interactions can occur, including an increased likelihood for bleeding.

\section{Feverfew}

Feverfew is a herb used for centuries in Europe with the intent for treatment of rheumatoid arthritis and migraine headaches. The active principles, sesquiterpene lactone - parthenolide and flavanoid glycosides, have anti-inflammatory properties [55]. Double-blind placebocontrolled studies have shown no apparent difference in clinical response between oral feverfew capsules and placebo at six weeks [56]. Sublingual feverfew may be effective in aborting mild migraine headaches when used as prophylaxis [57]. Active components of feverfew are known to inhibit platelet function and can increase bleeding risk [58].

\section{Cranberries}

Cranberries are available as the fresh or dried fruit and marketed as juice, jam, or sauce. Their properties qualify them as a super fruit based on the antioxidant properties. Cranberries are rich in vitamin C, fiber, minerals, and polyphenol antioxidants, with anticoagulant and antiinfective actions. Cranberries have earned a reputation for being effective in the prevention of urinary tract infection, based on their ability to decrease the Escherichia coli and other fimbriated bacterial adherence to the bladder and urethral epithelium or through biofilm formation. Commercially, cranberries are marketed as juice, powder, and capsules for this purpose. Cranberry juice and cranberry-containing products are effective in reducing the incidence of urinary tract infections post-renal transplant [59-61]. The active bactericidal component of cranberry juice is proanthocyanidin [62]. Cranberry gel in high concentration has an inhibitory effect on streptococci and dental plaque formation [63]. Polyphenol components of cranberry juice have significant antioxidant properties and cardiovascular health benefits [64]. Cranberry juice interacts with warfarin to increase the INR and potentiate the drug effect $[65]$. 


\section{Cureus}

\begin{tabular}{|c|c|c|c|}
\hline & Indication & Evidence & Adverse Effects \\
\hline $\begin{array}{l}\text { Echinacea } \\
\text { [27-28] }\end{array}$ & Upper respiratory tract infections & Inconclusive & Not significant; drug interactions \\
\hline Ginseng [29] & $\begin{array}{l}\text { Cognitive and physical } \\
\text { performance }\end{array}$ & Inconclusive & Not significant; drug interactions \\
\hline $\begin{array}{l}\text { Peppermint } \\
\text { [43] }\end{array}$ & $\begin{array}{l}\text { Flavoring agent; used for } \\
\text { gastrointestinal manifestations }\end{array}$ & Inconclusive & Not significant \\
\hline Ginger [44] & $\begin{array}{l}\text { Flavoring agent; for upper } \\
\text { gastrointestinal complaints }\end{array}$ & Inconclusive & Not significant; drug interactions \\
\hline $\begin{array}{l}\text { Chamomile } \\
\text { [46-48] }\end{array}$ & $\begin{array}{l}\text { Emollient for skin; for } \\
\text { gastrointestinal disturbances }\end{array}$ & Inconclusive & Allergic reactions \\
\hline $\begin{array}{l}\text { Saw palmetto } \\
\text { [51-53] }\end{array}$ & Benign prostatic hyperplasia & Inconclusive & Not significant; coagulopathy \\
\hline $\begin{array}{l}\text { Ginkgo } \\
\text { biloba [31-36] }\end{array}$ & Dementia and claudication & May be effective & Bleeding, seizures in epileptics \\
\hline Garlic [37-39] & Hypercholesterolemia & May be effective & $\begin{array}{l}\text { Bleeding (platelet dysfunction), } \\
\text { bad breath and sweat. }\end{array}$ \\
\hline $\begin{array}{l}\text { St. John's } \\
\text { wort [40-42] }\end{array}$ & Depression & May be effective & $\begin{array}{l}\text { Significant drug - drug } \\
\text { interactions }\end{array}$ \\
\hline Soy [45] & $\begin{array}{l}\text { Menopausal symptoms and } \\
\text { hypercholesterolemia }\end{array}$ & $\begin{array}{l}\text { May be effective for } \\
\text { hypercholesterolemia }\end{array}$ & $\begin{array}{l}\text { Long-term estrogen related } \\
\text { effects not clear }\end{array}$ \\
\hline $\begin{array}{l}\text { Kava kava } \\
\text { [49-50] }\end{array}$ & $\begin{array}{l}\text { Anxiety and psycho stimulant } \\
\text { effects }\end{array}$ & May be effective & $\begin{array}{l}\text { Hepatic and renal dysfunction, } \\
\text { hematological }\end{array}$ \\
\hline $\begin{array}{l}\text { Feverfew [55- } \\
58 \text { ] }\end{array}$ & Anti-inflammatory effects & $\begin{array}{l}\text { May be effective for } \\
\text { migraine prophylaxis }\end{array}$ & Bleeding (platelet dysfunction) \\
\hline
\end{tabular}

TABLE 1: Herbal preparations used in the U.S, perceived benefits and effects 


\section{Cureus}

patient's complete list of herbals, along with prescribed and over-the-counter medications to minimize interactions. This review is necessary with the presentation of a new manifestation

(Table 2). Drug interactions with herbals are more likely to occur with medications that have a narrow therapeutic index, such as warfarin and digoxin [69].

\begin{tabular}{|l|l|l|}
\hline Herb & Bleeding Risk & Precautions \\
\hline Cranberry juice & Increased & Careful monitoring of INR and for bleeding \\
Ginkgo biloba & Increased & Careful monitoring of INR and for bleeding \\
Garlic & Increased (through anti-platelet properties) & Careful monitoring for bleeding \\
Ginger & Variable or increased & Monitor for bleed while on warfarin, antiplatelet drugs \\
Ginseng & Variable or decreased & Monitor the INR \\
\hline
\end{tabular}

\section{TABLE 2: Bleeding Risk from Warfarin-Dietary Supplement Interaction}

In an extensive review of herbs and dietary supplement interactions, the top five herbs or botanical products with the most interactions included St. John's wort, ginkgo, kava kava, digitalis, and willow [70]. St. John's wort in particular decreased the effectiveness of several medications through the CYP3A4 pathway; it lowers the effectiveness of benzodiazepines and warfarin, while it increased the risk for serotonin syndrome [70].

\section{Caffeine}

Caffeine is an adenosine receptor antagonist stimulant in the central nervous system; the stimulant properties influence the muscular, respiratory, and cardiovascular systems. Caffeine is metabolized by cytochrome P $4501 \mathrm{~A} 2$. Caffeine is one of the few items available naturally but can be also added to a variety of food items that we consume; hence, it may be considered as a nutrient or a drug that can be used or abused, with the potential to induce intoxication and withdrawal effects [71]. In fact, caffeine is the most common psycho-stimulant drug worldwide [72]. Caffeine abuse must be considered when a patient presents with tremors, sweating, insomnia, or abdominal symptoms such as nausea, vomiting, or diarrhea; the diagnosis can be easily missed or mistaken for other disorders at time of presentation [73]. Because of abuse potential, a proposal has been made for the maximum levels of caffeine allowable in the urine for sporting competitions [74]. The effects of caffeine with an individual are highly variable, depending on daily intake, metabolism, and body weight. "Caffeinism" is a syndrome that occurs in excessive and long-term abusers; the syndrome is characterized by depression, restlessness, anxiety, palpitations, and poor performance [75]. An intake of 1,000 to 1,500 mg of caffeine daily can result in caffeinism. The Food and Drug Administration considers an intake of 1,000 mg daily as a toxic dose. Withdrawal from caffeine results in drowsiness, insomnia, irritability, headache, and fatigue, beginning a day or two after withdrawal and lasting up to a week [76]. While acute intake of caffeine can cause diuresis, chronic intake may not be associated with the manifestation. The relationship of coffee or caffeine to gallstone disease has been debated, with suggestions of possibly even a favorable effect [77]. A recent Mayo Clinic study indicated that heavy coffee consumption, defined as more than 28 cups of coffee per week (a cup being $8 \mathrm{oz}$ ), was associated with increased risk of all-cause mortality in men and women $<55$ years; the findings call for caution in younger people [78]. Coffee 


\section{Cureus}

consumption in excess of three cups a day was also associated with increased mortality in women with breast cancer; whether coffee intake was a surrogate marker for fatigue and poor sleep is not clear [79]. In a systematic review of patients with chronic liver disease, caffeine consumption decreased progression to cirrhosis, risk of mortality in cirrhosis, and progression to hepatocellular carcinoma [80].

Caffeine is rapidly absorbed in the small intestine and metabolized in the liver by the CYP450 system; the half-life is highly variable, and influenced by medications the person may be on and also by smoking. Caffeine activates several neurotransmitter systems in the brain through a complex mechanism [72]. Interestingly, a French study of nearly 2,500 women age 65 and older suggested that caffeine intake was related to moderately better cognitive maintenance over a period of five years in older women with vascular disorders [81]. Thus, a simple or straight conclusion on caffeine intake and health effects may not be easy to make.

Manufacturers of caffeine containing products are expected to state clearly the content of caffeine, the quantity considered safe for consumption, and health risks of chronic use of caffeine [82]. Caffeine is a common ingredient of energy drinks. Mixing alcohol and caffeine is a particularly high-risk behavior [72]. Table 3 provides the caffeine count of commonly consumed items, while Table 4 lists the properties of caffeine.

Over-the-Counter Product

Anacin

Excedrin

Caffeine tablet

Beverages and Food

Coca-Cola

Pepsi

Green tea

Dunkin’ Donuts Coffee

Starbucks Coffee

Starbucks Hot Chocolate

Mountain Dew

5-Hour Energy

Red Bull

Hershey's Special Dark

Coffee ice cream
Tablet or Serving

1 tablet

1 tablet

1 tablet

Volume

12 oz.

12 oz.

$8 \mathrm{oz}$.

14 oz.

$12 \mathrm{oz}$.

16 oz.

12 oz.

$1.9 \mathrm{oz}$.

$8.4 \mathrm{oz}$.

$1.5 \mathrm{oz} \mathrm{bar}$

4 oz.

\section{Caffeine (mgs)}

32

65

$100-200$

Caffeine (mgs)

35

38

$35-60$

178

260

35

54

208

80

31

$25-30 \mathrm{mg}$

TABLE 3: Caffeine Content of Commonly Consumed Products 


\section{Cureus}

\begin{tabular}{|c|c|}
\hline Source & An alkaloid derivative of the coffee plant, tea bush and other sources \\
\hline Half-life & For caffeine is about five hours \\
\hline Bioavailability & Nearly $100 \%$ \\
\hline Metabolism & Hepatic, by the CY450 system \\
\hline Protein binding & Less than a third of caffeine in blood \\
\hline Excretion & Almost completely renal, via the urine \\
\hline Tolerance & Usual tolerated amounts are below 500 mg/day \\
\hline Toxicity & $\begin{array}{l}\text { Occurs in doses above } 1000 \mathrm{mg} / \text { daily, ingested over time. Caffeinism may occur with a daily } \\
\text { intake of } 1000-1500 \mathrm{mg} \text { over time }\end{array}$ \\
\hline Effects & $\begin{array}{l}\text { Can be positive and negative, including arousal and motor activation. Cognitive effects vary } \\
\text { markedly, and are influenced by several variables }\end{array}$ \\
\hline $\begin{array}{l}\text { Addiction and } \\
\text { dependence }\end{array}$ & Can result following chronic ingestions of caffeine \\
\hline
\end{tabular}

TABLE 4: Caffeine: Properties

Alcohol

Alcohol, although not a dietary supplement, is discussed here in view of its common interactions with nutrients, drugs and supplements, and its inclusion in many energy drinks. Alcohol is metabolized in the liver. Partly due to the hepatic biochemical reactions involving numerous other substances besides alcohol, interactions are only more likely. The relationship of chronic alcohol intake to cirrhosis is well-recognized [83]. Alcohol metabolism produces acetaldehyde, which results in nonspecific modification of nucleic acids and proteins [84]. Alcohol consumption along with use of tobacco and betel chewing is associated with increased oral cancer risk [85]; alcohol intake is a risk factor for pancreatitis and pancreatic cancer, especially in the presence of additional risk factors, such as amount and duration of use, heredity, autoimmune factors, and smoking. The risk increases with dose in relation to specifics of food intake, nutrient depletion, fasting or fed state, and other factors [86]. Alcohol abuse alters brain neurophysiology, causing acute and chronic injury to several areas of the brain; it may even be a risk factor for suicide [87]. Alcohol consumption is associated with decreased reaction time and motor vehicle accident fatality [88].

Heavy alcohol consumption is always harmful; but a fair amount of alcohol intake may be associated with some health benefits, particularly relating to cardiovascular morbidity and mortality [89]. The maximum daily consumption varies with country: recommended maximum daily intake of alcoholic beverages is two/day in Australia $(20 \mathrm{gm} / \mathrm{d})$, one to two/day in Japan (19.75 - $39.5 \mathrm{gm} / \mathrm{d})$, two/day in Canada (13.6 - $27.2 \mathrm{gm} / \mathrm{d})$, and one to two/day in the U.S. (14 $28 \mathrm{gm} / \mathrm{d}$ ). Example: Wine bottles in the United States are sold in fifths of a gallon or volume of $750 \mathrm{ml}$, which is equivalent to 25.36 fluid ounces. One wine bottle ( $5 \%$ alcohol) contains $750 \mathrm{X}$ $5 \%$ X 0.8 grams of alcohol (30 grams of alcohol). Primary care providers should take responsibility to teach their patients about maximum daily alcohol consumption. Yet, one 


\section{Cureus}

should never make a recommendation to a patient to begin or continue drinking. Women are more prone to get effects from alcohol due to lower body size, lower body water, and lower activity of gastric alcohol dehydrogenase when compared to men. Hence, the maximum daily intake of alcohol should be lower in women.

In particular, patients with liver disease (e.g. hepatitis or cirrhosis), diabetics on certain oral anti-diabetic drugs, those on sleep medications, warfarin, antibiotics, anti-seizure medications, and antidepressants should take particular caution with drinking, and avoid alcohol intake when possible. Binge drinking is always harmful. The difference between the health benefits of wines and other alcohol beverages, and between red and white wine remains controversial (Table 5) 


\section{Cureus}

\begin{tabular}{|c|c|}
\hline \multirow{4}{*}{ Heart } & Cardiomyopathy \\
\hline & High output heart failure \\
\hline & Hypertension \\
\hline & Atrial and ventricular arrhythmias \\
\hline \multirow{3}{*}{ Gastrointestinal and liver } & Acute hepatitis, fatty liver, chronic liver disease (cirrhosis) \\
\hline & Alcoholic gastritis, peptic ulcer, Mallor Weiss tears \\
\hline & Chronic pancreatitis \\
\hline \multirow{2}{*}{ Muscle } & Myopathy \\
\hline & Rhabdomyolysis \\
\hline \multirow{7}{*}{ Nervous system } & Alcohol related seizures \\
\hline & Sleep disturbances \\
\hline & Sadness, psychotic disorders \\
\hline & Dementia and delirium \\
\hline & Wernicke's encephalopathy, Korsakoff's psychosis \\
\hline & Degeneration of corpus callosum and the cerebellum \\
\hline & Peripheral neuropathy \\
\hline \multirow{4}{*}{ Hematological } & Macrocytosis \\
\hline & Nutrient deficiency anemia \\
\hline & Hemolytic anemia \\
\hline & Thrombocytopenia \\
\hline \multirow{2}{*}{ Nutritional } & Micronutrient or macronutrient deficiencies \\
\hline & Beer drinkers potomania with hyponatremia \\
\hline \multirow{4}{*}{ Miscellaneous } & Accidents and trauma \\
\hline & Withdrawal effects, including seizures and delirium tremens \\
\hline & Alcohol-related sexual dysfunction, infertility \\
\hline & Both abuse and dependence behavior with related social consequences \\
\hline
\end{tabular}

TABLE 5: Alcoholism and Consequences 
The term "energy drink" refers to a drink with stimulant ingredients, with claims to promote physical and mental energy. Often, the drink is a concentrated liquid with a variety of "ingredients having or claimed to have the property to increase the liveliness and energy" [90]. Caffeine is a common ingredient in energy drinks.

Carbonated beverages and energy drinks are available unrestricted, and their popularity driven by ad campaigns promoting their use in the general population. Consequences of careless or excessive consumption include addiction potential due to nicotine, diabetes from increased calorie intake in an era of obesity epidemic, and other organ or system impairments [91]. Based on the International Society of Sports Nutrition (ISSN) stance on energy drinks, the primary nutrients in energy drinks are carbohydrate and caffeine. Consumption of caffeine and carbohydrates can increase alertness and performance if taken half to one hour before the desired time of effect. Patients with preexisting illness, such as diabetes mellitus and cardiovascular disease in particular, should exercise caution, as they may experience hyperglycemia and adverse cardiac effects [92-94].

Despite claims that energy drinks enhance or improve cognition, evidence-based data supporting the claims are limited; any benefits may also be extrapolated to ingredients in the drink, such as carbohydrates and caffeine [95]. Secondary ingredients in the energy drinks like taurine, glucoronolactone, guarana, and B vitamins are claimed to improve aerobic metabolism, although unproven by scientific data [94].

While benefits remain questionable, adverse events continue to be reported. Seizures and ischemic stroke following consumption of significant amounts of energy drinks in a person without prior risk factors for vascular disease have been reported [96]. Energy drinks mixed with alcohol are available in the market; the combination may give a false sense of alertness while intoxicated and may even be harmful [97]. Excessive consumption of caffeine in energy drinks is associated with adverse effects including hypertension, tachycardia, and rhythm irregularities, anxiety, dependence and addiction, and in large doses, even death. In fact, heavy coffee consumption, defined in a study as more than 28 cups of coffee per week, a cup being 8 oz, is associated with increased risk of all-cause mortality in men and women $<55$ years, urging caution also in younger people [78].

Caffeine consumption in a large dose with other ingredients, over a short span of time, may cause adverse effects; this aspect needs further study. Many energy drinks do not reveal the exact caffeine content. There is now a change in perception of energy drinks from harmless to mild stimulant to lethal; they are unregulated, and blood levels of caffeine can become high or at times even lethal from the consumption of 3-10 gm. of caffeine with these drinks [98]. As most of energy drinks are aimed at active adults in the setting of easy and widespread availability in the market with loose regulations, children and adolescents should not take liberties with regards to use of unstudied formulations without parental consent [99-101].

Surprisingly, an amphetamine derivative, 1,3-dimethylamylamine (DMAA), is an ingredient of about 200 sports supplements which have large sales in the U.S.; it had been earlier withdrawn as an approved pharmaceutical $[7,101)$. DMAA has been implicated in numerous adverse events including but not limited to panic attacks, seizures, cardiac disorders, and death, and in other countries, even in a hemorrhagic stroke [7]. There is a tendency to term several such products as naturally-derived, giving an undue sense of security. The need for energy drink users in all age groups to exercise caution deserves emphasis.

Nuts

Nuts are a worthwhile inclusion in the diet of patients with metabolic syndrome and diabetes, 
as data provides support for improved glycemic control and decreased cardiovascular risk [102]. Nut consumption four times a week has been demonstrated to decrease risk for coronary artery disease by $37 \%$ based on four large prospective studies [103]. The Nurses' Health Study attributed the decreased risk of diabetes mellitus and coronary artery disease following nut consumption to the large amounts of polyunsaturated fatty acids (PUFA) and monounsaturated fatty acids (MUFA) in nuts [104-105].

Pistachios offer multifold benefit, promote heart healthy lipid profile, manifest by increase in HDL, decrease in LDL and total cholesterol, decrease in triglycerides, decline in LDL/HDL ratio, and decrease in total cholesterol/HDL ratio. Fiber and protein rich pistachio nuts also aid in weight loss by increasing satiety and negating the postprandial glycemic response to carbohydrate rich food; nuts also have anti-inflammatory and antioxidant properties [106-107]. Pistachios can be consumed as a snack with portion control for individuals with concern for weight gain [108].

Almonds lower serum total cholesterol, LDL cholesterol concentration, and total cholesterol/HDL ratio while preserving HDL cholesterol [109]. Almonds are a great source of fiber, vitamins, and minerals, especially vitamin E and B complex, iron, calcium, potassium, zinc, and magnesium, and are gluten-free.

Walnuts contain the highest amount of antioxidants compared to other nuts and are considered heart healthy [110]. Pecans are rich in monounsaturated fatty acids (oleic acid), B vitamins, and minerals similar to almonds. Cashew nuts contain about 500 calories/100 grams; they are a source of monounsaturated fatty acids, zinc, selenium, and copper. Peanuts are rich in energy and contain high quality amino acids and proteins. Peanuts contain polyphenols with properties that may be anti-cancer and offer protection against vascular disease.

In summary, most nuts contain monounsaturated fats (that lower LDL cholesterol), omega-3 fatty acids, fiber, plant sterols, and vitamin $\mathrm{E}$. While omega- 3 fatty acids are good sources through fish consumption, nuts are the best plant source. Nuts have a very low glycemic index, ranging from 14 for peanuts to 21 for cashews [111]. Although nuts are a source of fiber, fat, protein, and carbohydrate, they are not recognized as a carbohydrate source; the low glycemic index limits a rapid rise in glucose after consumption. The properties change when cooked, roasted in oil, or taken with honey. A handful of nuts a day may be a good way towards becoming heart healthy!

\section{Vitamins}

As a general approach, the intake of vitamins must meet the Dietary Reference Intake (DRI), including the Recommended Dietary Allowance (DRA) and Adequate Intakes (AI), based on the Food and Nutrition Board, Institute of Medicine [112].

Damage to the cell and cell organelles by free radicals and oxidative damage is one accepted mechanism of mutation-causing cancer. Examples of antioxidants include vitamin E, vitamin C, beta carotene, lycopene, lutein, zeaxanthin, zinc, and selenium. Antioxidants, as dietary supplements, may help in reducing the risk of cancer, though data thus far have not confirmed a decrease in the incidence of cancer or mortality risk. More important, some antioxidants in high doses may even increase mortality in certain cancers; e.g., beta carotene may enhance the progression of lung cancer, especially in smokers [113-114]. The B vitamins, such as B12, B6, and folic acid, have not demonstrated a decline in risk of prostate cancer, transient ischemic attacks, or stroke, in spite of a decline in homocysteine levels [115-117].

The association between dietary consumption of vitamins, fatty acids, and minerals and the risk 
of colorectal cancer has been studied but failed to yield any significant association [118]. Fenretinide, a pro-oxidant vitamin A derivative, and vitamin A supplementation have shown promise in lowering breast cancer risk, but further studies need to be done to validate the conclusion [119-120]. Vitamins and Lifestyle Study (VITAL Study) suggests increased risk of lung cancer with long-term use of beta carotene, lutein, and retinol supplementation; they are not recommended in smokers [121]. No association has been found between dietary intake of vitamins, supplements, carotenoids, vegetables, and fruits and pancreatic cancer [122]. Fruit and vegetable consumption might be associated with a lower risk of renal cell cancer in men [123]. A benefit from the intake of fruits and vegetables may also be seen for bladder cancer [124]. A systematic review by the United State Preventive Service Task Force (USPSTF) revealed that vitamin and mineral supplement consumption did not result in a significant benefit for the primary prevention of cardiovascular disease or cancer [125]. Based on the Physician's Health Study-2, daily multivitamin supplementation for over 12 years did not benefit cognition compared to placebo [126]. Multivitamins and mineral supplements in high doses did not demonstrate benefit in the secondary reduction of cardiovascular events, such as myocardial infarction, even though the study was limited by non-adherence [127].

\section{Misuse and megadoses of vitamins}

The RDA for vitamins, as provided by the Institute of Medicine (IOM), is followed in the United States and Canada. Regular multivitamin pills differ from mega vitamins in the sense that the latter refers to high doses of vitamins as compared to standard multivitamin pills. The Women's Health Initiative study has shown no link between multivitamin supplementation and risk of lung cancer, colorectal cancer, breast cancer, endometrial cancer, ovarian cancer, and cardiovascular and total mortality in postmenopausal women [128]. The Iowa Women's Health Study of 38,772 older women confirmed that many commonly used dietary vitamin and mineral supplements may be associated with increased total mortality risk; the association was strongest with iron, while calcium was associated with diminished risk [129]. An accompanying editorial commented that the use of vitamins and mineral supplements couldn't be recommended as a preventive measure, at least not in well-nourished people; and that supplements do not replace the value of fruit and vegetable consumption [130]. On the other hand, in a male Physicians' Health Study, a randomized controlled trial over 11.2 years, daily multivitamins supplementation modestly reduced the risk of total cancer [131].

Over a billion upper respiratory infections occur in the U.S. each year. Numerous remedies are tried to prevent or treat the common cold, including echinacea, zinc, garlic, antihistamines, and vitamin C [132]. The Third National Health and Nutrition Examination Survey (NHANES) data suggested an inverse association between vitamin D levels below $10 \mathrm{ng} / \mathrm{ml}$ and recent upper respiratory infections [132]. A randomized controlled study over 18 months suggested that monthly administration of 100,000 IU vitamin D did not reduce the incidence or severity of upper respiratory tract infections in healthy adults [133]. A meta-analysis suggests that mega dose prophylaxis with vitamin $C$ does not reduce the incidence of the common cold in the normal population [134]. Neither is there any evidence for antitumor activity with the use of megadose vitamin C so far [135]. High-dose vitamin C used over time resulted in a dosedependent increased likelihood of stone formation in men [136]. While most of the vitamins do not have maximum upper intake levels, megadoses of Vitamins A, C, D, and E can cause harmful manifestations [136-137].

Hypervitaminosis A results from excessive consumption of fish oils and mega vitamins. Multivitamins contain about 10,000 IU of Vitamin A; if consumed on a daily recommended basis, toxic effects do not occur. The Lowest Observed Adverse Effect Level (LOAEL) over a prolonged period is 21,600 IU, according to the U.S. Institute of Medicine [138] (Table 6). 


\section{Cureus}

\begin{tabular}{|l|l|}
\hline \multicolumn{1}{|c|}{} & Nausea and vomiting \\
\hline Vitamin A & Headache (idiopathic intracranial hypertension), dizziness, blurred vision \\
& Loss of muscular coordination \\
& Nausea, vomiting, diarrhea \\
Vitamin C & Flushing, headache \\
& Kidney Stones \\
& Vomiting, decreased appetite, constipation \\
Vitamin D & Fatigue, muscle weakness \\
& Hypercalcemia, kidney stones \\
Vitamin E & Increased bleeding \\
& Hypertriglyceridemia \\
\hline
\end{tabular}

TABLE 6: Consequences of Hypervitaminosis

The 2010 recommendations of the Institute of Medicine (IOM) place the RDA for vitamin D at $600 \mathrm{IU} / \mathrm{d}$ below the age of 70 years and at $800 \mathrm{IU} / \mathrm{d}$ above that age. The upper limit for toxicity for vitamin $\mathrm{D}$ is $4,000 \mathrm{IU} / \mathrm{d}$, based on the IOM report. Acute overdose is observed at doses above $600,000 \mathrm{IU} / \mathrm{d}$ for several days to months. [139]. An Australian study demonstrated that monthly doses of vitamin D at 500,000 IU for a year resulted in hypercalcemia, falls and fractures [140]. Vitamin E supplementation at 1,600 IU may be tolerated short-term, but long-term use is controversial and even may be harmful; in the presence of chronic diseases, long-term use of Vitamin $\mathrm{E}$ at over $400 \mathrm{IU} / \mathrm{d}$ may increase the incidence of heart failure and mortality [141]. In high doses, vitamin E can act as an anticoagulant and increase the risk of bleeding [142]. Although this review has focused on vitamins and not minerals, it must be stated that the use of calcium supplements has become a topic of controversy of late. High intake of calcium as a supplement was associated with excess risk of cardiovascular death in men, but not women, in the National Institutes of Health - AARP Diet and Health Study [143].

\section{Conclusions}

Herbal supplements, unlike prescribed medications, are not regulated by the FDA and are often marketed with little premarketing safety data. Products may be contaminated by other ingredients; there may be batch-to-batch variations, or even within the same batch.

St. John's wort, garlic, soy, and kava kava may have predictable effects, yet should be used with knowledge of adverse effects. Bleeding risk or diminished effect with warfarin or antiplatelet agents should remain a concern when using cranberry juice, ginkgo, garlic, ginger, ginseng, and saw palmetto.

Excessive or careless use of caffeine in any form, especially with alcohol, and energy drinks have abuse potential and significant adverse effect profiles. Nuts, which are rich in unsaturated fatty acids, fiber, minerals, and vitamins, besides having a very low glycemic index, are 
recognized as heart healthy. Natural forms of vitamins and antioxidants from the diet may prevent certain forms of cancer. Megadose usage of vitamins A, C, D, and E can carry harmful effects.

Providers can no longer choose to ignore patient queries regarding CAM. Providers must understand the scientific evidence regarding the benefits and harms of herbals, supplements, and vitamins; the products can be used intelligently by being an informed consumer. Even as CAM and conventional medicine have their identities, traditions, and practitioners, integration of CAM and conventional medicine is beginning to occur in many settings [5].

\section{Additional Information}

\section{Disclosures}

Conflicts of interest: In compliance with the ICMJE uniform disclosure form, all authors declare the following: Payment/services info: All authors have declared that no financial support was received from any organization for the submitted work. Financial relationships: All authors have declared that they have no financial relationships at present or within the previous three years with any organizations that might have an interest in the submitted work. Other relationships: All authors have declared that there are no other relationships or activities that could appear to have influenced the submitted work.

\section{References}

1. U.S. Department of Health and Human Services. National Institute of Health. Complementary, alternative or integrative health: What's in a name?. (2012). Accessed: July 6, 2013: http://nccam.nih.gov/health/whatiscam.

2. Neldner KH: Complementary and alternative medicine. Dermatol Clin. 2000, 18:189-93. 10.1016/S0733-8635(05)70159-5

3. Furnham A: Complementary and alternative medicine. Psychologist. 2002, 15:228-231.

4. U.S. Department of Health and Human services. U.S. Food and Drug Administration. What is a dietary supplement?. (2009). Accessed: November 2, 2013: http://www.fda.gov/aboutfda/transparency/basics/ucm195635.htm.

5. Institute of Medicine (US) Committee on the Use of Complementary and Alternative Medicine by the American Public: Executive summary. Complementary and Alternative Medicine in the United States. Institute of Medicine (US) (ed): The National Academies Press, Washington, DC; 2005. 1-12.

6. Marcus DM, Grollman AP: The consequences of ineffective regulation of dietary supplements . Arch Intern Med. 2012, 172:1035-6. 10.1001/archinternmed.2012.2687

7. Cohen PA: DMAA as a dietary supplement ingredient. Arch Intern Med. 2012, 172:1038-9. 10.1001/archinternmed.2012.1677

8. Harel Z, Harel S, Wald R, Mamdani M, Bell CM: The frequency and characteristics of dietary supplement recalls in the United States. JAMA Intern Med. 2013, 173:926-8. 10.1001/jamainternmed.2013.379

9. Reichenbach S, Jüni P: Medical food and food supplements: Not always as safe as generally assumed. Ann Intern Med. 2012, 156:894-5. 10.7326/0003-4819-156-12-201206190-00012

10. González-Stuart A: Herbal product use by older adults . Maturitas. 2011, 68:52-5. 10.1016/j.maturitas.2010.09.006

11. Rhee SM, Garg VK, Hershey CO: Use of complementary and alternative medicines by ambulatory patients. Arch Intern Med. 2004, 164:1004-9.

12. Konik EA, Jungling RC, Bauer BA: Herbs and dietary supplements in the European Union: a review of the regulations with special focus on Germany and Poland. J Diet Suppl. 2011, 8:4357. 10.3109/19390211.2010.547243

13. Qato DM, Alexander GC, Conti RM, Johnson M, Schumm P, Lindau ST: Use of prescription and over-the-counter medications and dietary supplements among older adults in the United States. JAMA. 2008, 300:2867-78. 10.1001/jama.2008.892

14. Upchurch DM, Chyu L: Use of complementary and alternative medicine among American 
women. Womens Health Issues. 2005, 15:5-13.

15. Barnes PM, Powell-Griner E, McFann K, Nahin RL: Complementary and alternative medicine use among adults: United States, 2002. Adv Data. 2004, 343:1-19.

16. Loya AM, González-Stuart A, Rivera JO: Prevalence of polypharmacy, polyherbacy, nutritional supplement use and potential product interactions among older adults living on the United States-Mexico border: A descriptive, questionnaire-based study. Drugs Aging. 2009, 26:42336. 10.2165/00002512-200926050-00006

17. Heller T, Muller N, Kloos C, Wolf G, Müller UA: Self medication and use of dietary supplements in adult patients with endocrine and metabolic disorders. Exp Clin Endocrinol Diabetes. 2012, 120:540-6. 10.1055/s-0032-1311640

18. Mehta DH, Gardner PM, Phillips RS, McCarthy EP: Herbal and dietary supplement disclosure to health care providers by individuals with chronic conditions. J Altern Complement Med. 2008, 14:1263-9. 10.1089/acm.2008.0290

19. Laditka JN, Laditka SB, Tait EM, Tsulukidze MM: Use of dietary supplements for cognitive health: results of a national survey of adults in the United States. Am J Alzheimers Dis Other Demen. 2012, 27:55-64. 10.1177/1533317511435662

20. Tang CT, Belani LK, Das S, Jaafar MZ: Treatment of dementia with herbs: A short review . Clin Ter. 2013, 164:43-6. 10.7417/T.2013.1511

21. Cheng KC, Li YX, Cheng JT: The use of herbal medicine in cancer-related anorexia/ cachexia treatment around the world. Curr Pharm Des. 2012, 18:4819-26.

22. Olsen NJ: Nutraceuticals for the treatment of osteoarthritis. Minerva Med. 2011, 102:33-40.

23. Grubbs V, Piantinga LC, Tuot DS, et al.: Americans' use of dietary supplements that are potentially harmful in CKD. Am J Kidney Dis. 2013, 61:739-47. 10.1053/j.ajkd.2012.12.018

24. Bunchorntavakul C, Reddy K: Review article: Herbal and dietary supplement hepatotoxicity . Aliment Pharmacol Ther. 2013, 37:3-17. 10.1111/apt.12109

25. Teschke R, Schulze J, Schwarzenboeck A, Eickhoff A, Frenzel C: Herbal hepatotoxicity: Suspected cases assessed for alternative causes. Eur J Gastroenterol Hepatol. 2013, 25:1093-8. 10.1097/MEG.0b013e3283603e89

26. Bailey RL, Gahche JJ, Miller PE, Thomas PR, Dwyer JT: Why US adults use dietary supplements. JAMA Intern Med. 2013, 173:355-61. 10.1001/jamainternmed.2013.2299

27. Linde K, Barrett B, Wolkart K, Bauer R, Melchart D: Echinacea for preventing and treating the common cold. Cochrane Database Syst Rev. 2006, Jan 25:CD000530.

28. Woelkart K, Linde K, Bauer R: Echinacea for preventing and treating the common cold . Planta Med. 2008, 74:633-7. 10.1055/s-2007-993766

29. Vogler BK, Pittler MH, Ernst E: The efficacy of ginseng. A systematic review of randomised clinical trials. Eur J Clin Pharmacol. 1999, 55:567-75.

30. Gunturu SG, Dharmarajan TS: From drug nutrient interactions. Geriatric Gastroenterology. Pitchumoni CS, Dharmarajan TS (ed): Springer, New York; 2012. 89-98.

31. DeKosky ST, Williamson JD, Fitzpatrick AL, et al.: Ginkgo biloba for prevention of dementia: A randomized controlled trial. JAMA. 2008, 300:2253-62. 10.1001/jama.2008.683

32. Oken BS, Storzbach DM, Kaye JA: The efficacy of ginkgo biloba on cognitive function in Alzheimer disease. Arch Neurol. 1998, 55:1409-15.

33. Solomon PR, Adams F, Silver A Zimmer J, DeVeaux R: Ginkgo for memory enhancement: A randomized controlled trial. JAMA. 2002, 288:835-40.

34. Pittler MH, Ernst E: Ginkgo biloba extract for the treatment of intermittent claudication: A meta-analysis of randomized trials. Am J Med. 2000, 108:276-81.

35. Birks J, Grimley Evans J: Ginkgo biloba for cognitive impairment and dementia . Cochrane Database Syst Rev. 2009, Jan. 21:CD003120. 10.1002/14651858.CD003120.pub3

36. Bent S, Goldberg H, Padula A, Avins AL: Spontaneous bleeding associated with ginkgo biloba: a case report and systematic review of the literature: a case report and systematic review of the literature. J Gen Intern Med. 2005, 20:657-61.

37. Stevinson C, Pittler MH, Ernst E: Garlic for treating hypercholesterolemia. A meta-analysis of randomized clinical trials. Ann Intern Med. 2000, 133:420-9.

38. Burnham BE: Garlic as a possible risk for postoperative bleeding . Plast Reconstr Surg. 1995, 95:213.

39. Rose KD, Croissant PD, Parliament CF, Levin MB: Spontaneous spinal epidural hematoma with associated platelet dysfunction from excessive garlic ingestion: A case report. Neurosurgery. 1990, 26:880-2. 
40. Linde K, Mulrow CD, Berner M, Egger M: St John's wort for depression. Cochrane Database Syst Rev. 2005, Apr 18:CD000448.

41. Linde K, Ramirez G, Mulrow CD, Pauls A, Weidenhammer W, Melchart, D: St John's wort for depression--an overview and meta-analysis of randomised clinical trials. BMJ. 1996, 313:2538.

42. Hammerness P, Basch E, Ulbricht C, et al.: St John's wort: a systematic review of adverse effects and drug interactions for the consultation psychiatrist. Psychosomatics. 2003, 44:27182.

43. Pittler MH, Ernst E: Peppermint oil for irritable bowel syndrome: A critical review and metaanalysis. Am J Gastroenterol. 1998, 93:1131-5.

44. Ernst E, Pittler MH: Efficacy of ginger for nausea and vomiting: A systematic review of randomized clinical trials. Br J Anaesth. 2000, 84:367-71.

45. Lethaby AE, Brown J, Marjoribanks G, Kronenberg F, Roberts H, Eden, J: Phytoestrogens for vasomotor menopausal symptoms. Cochrane Database Syst Rev. 2007, Oct 17:CD001395.

46. Srivastava JK, Shankar E, Gupta S: Chamomile: A herbal medicine of the past with bright future. Mol Med Rep. 2010, 3:895-901.

47. Amsterdam JD, Shults J, Soeller I, Mao JJ, Rockwell K, Newberg AB: Chamomile (Matricaria recutita) may provide antidepressant activity in anxious, depressed humans: An exploratory study. Altern Ther Health Med. 2012, 18:44-9.

48. Matić IZ, Juranić Z, Savikin K, Zdunić G, Nađvinski N, Gođevac D: Chamomile and marigold tea: Chemical characterization and evaluation of anticancer activity. Phytother Res. 2013, 27:852-8. 10.1002/ptr.4807

49. Pittler MH, Ernst E: Kava extract for treating anxiety. Cochrane Database Syst Rev. 2003, CD003383.

50. From the Centers for Disease Control and Prevention. Hepatic toxicity possibly associated with kava-containing products--United States, Germany, and Switzerland, 1999-2002. JAMA. 2003, 289:36-7.

51. Barry MJ, Meleth S, Lee JY, et al.: Effect of increasing doses of saw palmetto extract on lower urinary tract symptoms: A randomized trial. JAMA. 2011, 306:1344-51.

10.1001/jama.2011.1364

52. Avins AL, Lee JY, Meyers CM, Barry MJ; CAMUS Study Group: Safety and toxicity of saw palmetto in the CAMUS trial. J Urol. 2013, 189:1415-20. 10.1016/j.juro.2012.10.002

53. Hanaka M, Yoshi C, Yatera K, et al.: A case of rhabdomyolysis caused by saw palmetto of healthy foods (article in Japanese). J UOEH. 2012, 34:193-9.

54. Bonnar-Pizzorno RM, Littman AJ, Kestin M, White E: Saw palmetto supplement use and prostate cancer risk. Nutr Cancer. 2006, 55:21-7.

55. Pareek A, Suthar M, Rathore GS, Bansal V: Feverfew (Tanacetum parthenium L.): A systematic review. Pharmacogn Rev. 2011, 5:103-10. 10.4103/0973-7847.79105

56. Pattrick M, Heptinstall S, Doherty M: Feverfew in rheumatoid arthritis: A double blind, placebo controlled study. Ann Rheum Dis. 1989, 48:547-9.

57. Cady RK, Goldstein J, Nett R, Mitchell R, Beach, ME, Browning R: A double-blind placebocontrolled pilot study of sublingual feverfew and ginger (LipiGesic ${ }^{\mathrm{TM}} \mathrm{M}$ ) in the treatment of migraine. Headache. 2011, 51:1078-86. 10.1111/j.1526-4610.2011.01910.x

58. Heptinstall S, Groenwegen WA, Spangenberg P, Losche W: Inhibition of platelet behaviour by feverfew: A mechanism of action involving sulphydryl groups. Folia Haematol Int Mag Klin Morphol Blutforsch. 1988, 115:447-9.

59. Chen CS, Ho DR, Chang PJ, Lin Wy, Huang YC: Urine post equivalent daily cranberry juice consumption may opsonize uropathogenicity of Escherichia coli. J Infect Chemother. 2013, 19:812-7. 10.1007/s10156-013-0565-1

60. Pagonas N, Horstrup J, Schmidt D, et al.: Prophylaxis of recurrent urinary tract infection after renal transplantation by cranberry juice and L-methionine. Transplant Proc. 2012, 44:301721. 10.1016/j.transproceed.2012.06.071

61. Wang CH, Fang CC, Chen NC, et al.: Cranberry-containing products for prevention of urinary tract infections in susceptible populations: a systematic review and meta-analysis of randomized controlled trials. Arch Intern Med. 2012, 172:988-96. 10.1001/archinternmed.2012.3004

62. Afshar K, Stothers L, Scott H, MacNeily AE: Cranberry juice for the prevention of pediatric urinary tract infection: A randomized controlled trial. J Urol. 2012, 188:1584-7. 


\subsection{6/j.juro.2012.02.031}

63. Sethi R, Govila V: Inhibitory effect of cranberry juice on the colonization of Streptococci species: An in vitro study. J Indian Soc Periodontol. 2011, 15:46-50. 10.4103/0972-124X.82271

64. Basu A, Betts NM, Ortiz J, Simmons B, Wu M, Lyons TJ: Low-energy cranberry juice decreases lipid oxidation and increases plasma antioxidant capacity in women with metabolic syndrome. Nutr Res. 2011, 31:190-6. 10.1016/j.nutres.2011.02.003

65. Hamann GL, Campbell JD, George CM: Warfarin-cranberry juice interaction. Ann Pharmacother. 2011, 45:e17. 10.1345/aph.1P451

66. Mohammed Abdul MI, Jiang X, Williams KM, et al.: Pharmacodynamic interaction of warfarin with cranberry but not with garlic in healthy subjects. Br J Pharmacol. 2008, 154:1691-700. 10.1038/bjp.2008.210

67. Vaes LP, Chyka PA: Interactions of warfarin with garlic, ginger, ginkgo, or ginseng: Nature of the evidence. Ann Pharmacother. 2000, 34:1478-82.

68. Macan H, Uykimpang R, Alconcel M, et al.: Aged garlic extract may be safe for patients on warfarin therapy. J Nutr. 2006, 136:793S-795S.

69. Shi S, Klotz U: Drug interactions with herbal medicines. Clin Pharmacokinet. 2012, 51:77-104. 10.2165/11597910-000000000-00000

70. Tsai HH, Lin HW, Simon Pickard A, Tsai HY, Mahady GB: Evaluation of documented drug interactions and contraindications associated with herbs and dietary supplements: A systematic literature review. Int J Clin Pract. 2012, 66:1056-78. 10.1111/j.17421241.2012.03008.x

71. Pardo Lozano R, Alvarez Garcia Y, Barral Tafalla D, Farre Albaladejo M: Caffeine: A nutrient, a drug or a drug of abuse (article in Spanish). Adicciones. 2007, 19:225-38.

72. Ferre S: Caffeine and substance use disorders . J Caffeine Res. 2013, 3:57-58.

73. Ogawa N, Ueki H: Clinical importance of caffeine dependence and abuse. Psychiatry Clin Neurosci. 2007, 61:263-268.

74. Delbeke FT, Debackere M: Caffeine: Use and abuse in sports . Int J Sports Med. 1984, 5:179-82.

75. Gilliland K, Bullock W: Caffeine: A potential drug of abuse . Adv Alcohol Subst Abuse. 1983, 3:53-73.

76. Hughes JR, Oliveto AH, Helzer JE, Higgins ST, Bickel WK: Should caffeine abuse, dependence, or withdrawal be added to DSM-IV and ICD-10?. Am J Psychiat. 1992, 149:33-40.

77. Singh A, Pitchumoni CS: A critical review of coffee consumption and gallstone disease . Pract Gastroenterology. 2011, 35:36-47.

78. Liu J, Sui X, Lavie CJ, Herbert JR, et al.: Association of coffee consumption with all-cause and cardiovascular disease mortality. Mayo Clin Proc. Oct;88(10):. doi: . 2013, 88:1066-74. 10.1016/j.mayocp.2013.06.020

79. Lehrer S, Green S, Rosenzweig KE: Coffee consumption associated with increased mortality of women with breast cancer. J Caffeine Res. 2013, 3:38-40.

80. Saab S, Mallam D, Cox II, Gerald A, Tong MJ: Impact of coffee on liver diseases: A systematic review. Liver Int. 2014, 34:495-504. 10.1111/liv.12304

81. Vercambre MN, Berr C, Ritchie K, Kang JH: Caffeine and cognitive decline in elderly women at high vascular risk. J Alzheimers Dis. 2013, 35:413-21. 10.3233/JAD-122371

82. Ogawa N, Ueki H: Clinical importance of caffeine dependence and abuse. Psychiatry Clin Neurosci. 2007, 61:263-8.

83. Palmer TN: The biochemistry of alcohol and alcohol abuse . Sci Prog. 1989, 73:1-15.

84. Wallner M, Olsen RW: Physiology and pharmacology of alcohol: the imidazobenzodiazepine alcohol antagonist site on subtypes of GABAA receptors as an opportunity for drug development?. Br J Pharmacol. 2008, 154:288-98. 10.1038/bjp.2008.32

85. Petti S, Masood M, Messano GA, Scully C: Alcohol is not a risk factor for oral cancer in nonsmoking, betel quid non-chewing individuals. A meta-analysis update. Ann Ig. 2013, 25:314. 10.7416/ai.2013.1901

86. Herreros-Villanueva M, Hijona E, Banales JM, Cosme A, Bujanda L: Alcohol consumption on pancreatic diseases. World J Gastroenterol. 2013, 19:638-47. 10.3748/wjg.v19.i5.638

87. Ali S, Nathani M, Jabeen S, Yazdani I, Mouton CD, Bailey RK: Alcohol: The lubricant to suicidality. Innov Clin Neurosci. 2013, 10:20-9.

88. Callaghan RC, Gatley JM, Veldhuizen S, Lev-Ran S, Mann R, Asbridge M: Alcohol- or drug-use disorders and motor vehicle accident mortality: A retrospective cohort study. Accid Anal Prev. 2013, 53:149-55. 10.1016/j.aap.2013.01.008 
89. Jones A, McMillan MR, Jones RW, Kowalik GT, Steeden JA, Pruessner JC: Habitual alcohol consumption is associated with lower cardiovascular stress responses--a novel explanation for the known cardiovascular benefits of alcohol?. Stress. 2013, 16:369-76. 10.3109/10253890.2013.777833

90. Petit A, Levy F, Lejoyeux M, Reynaud M, Karila L: Energy drinks: An unknown risk (article in French). Rev Prat. 2012, 62:673-8.

91. Cichocki M: Energy drinks and their contribution to current health concerns for children and adolescents (article in Polish). Przegl Lek. 2012, 69:854-60.

92. La Bounty PM, Campbell Bl, Wilson J, et al.: International Society of Sports Nutrition position stand: Meal frequency. J Int Soc Sports Nutr. 2011, 8:4. 10.1186/1550-2783-8-4

93. McLellan TM, Lieberman HR: Do energy drinks contain active components other than caffeine?. Nutr Rev. 2012, 70:730-44. 10.1111/j.1753-4887.2012.00525.x

94. Pettitt RW, Niemeyer JD, Sexton PJ, Lipetzky A, Murray SR: Do the noncaffeine ingredients of energy drinks affect metabolic responses to heavy exercise?. J Strength Cond Res. 2013, 27:1994-9. 10.1519/JSC.0b013e3182736e31

95. Wilhelm P, Van Diepen MA, Nieuwenhuis L, Boulogne TL: The effect of energy drinks on the cognitive performance of adolescents (article in Dutch). Tijdschr Psychiatr. 2013, 55:57-62.

96. Dikici S, Saritas A, Besir FH, Tasci AH, Kandis H: Do energy drinks cause epileptic seizure and ischemic stroke?. Am J Emerg Med. 2013, 31:274.e1-4. 10.1016/j.ajem.2012.05.018

97. Pennay A, Lubman DI: Alcohol and energy drinks: A pilot study exploring patterns of consumption, social contexts, benefits and harms. BMC Res Notes. 2012, 5:369. 10.1186/17560500-5-369

98. Sepkowitz KA: Energy drinks and caffeine-related adverse effects . JAMA. 2013, 309:243-4.

99. Wolk BJ, Ganetsky M, Babu KM: Toxicity of energy drinks. Curr Opin Pediatr. 2012, 24:243-51. 10.1097/MOP.0b013e3283506827

100. Reissig CJ, Strain EC, Griffiths RR: Caffeinated energy drinks--A growing problem . Drug Alcohol Depend. 2009, 99:1-10. 10.1016/j.drugalcdep.2008.08.001

101. Gregory PJ: Availability of DMAA supplements despite US Food and Drug Administration action. JAMA Intern Med. 2013, 173:164-5. 10.1001/2013.jamainternmed.724

102. Kendall CW, Josse AR, Esfahani A, Jenkins DJ: Nuts, metabolic syndrome and diabetes. Br J Nutr. 2010, 104:465-73. 10.1017/S0007114510001546

103. Kelly JH Jr, Sabate J: Nuts and coronary heart disease: An epidemiological perspective. Br J Nutr. 2006, 96:S61-7.

104. Hu FB, Stampfer MJ, Manson JE, et al.: Frequent nut consumption and risk of coronary heart disease in women: Prospective cohort study. BMJ. 1998, 317:1341-5.

105. Jenkins DJ, Hu FB, Tapsell LC, Josse AR, Kendall CW: Possible benefit of nuts in type 2 diabetes. J Nutr. 2008, 138:1752S-1756S.

106. Dreher ML: Pistachio nuts: Composition and potential health benefits. Nutr Rev. 2012, 70:234-40. 10.1111/j.1753-4887.2011.00467.x

107. Edwards K, Kwaw l, Matud J, Kurtz l: Effect of pistachio nuts on serum lipid levels in patients with moderate hypercholesterolemia. J Am Coll Nutr. 1999, 18:229-32.

108. Li Z, Song R, Nguyen C, et al.: Pistachio nuts reduce triglycerides and body weight by comparison to refined carbohydrate snack in obese subjects on a 12-week weight loss program. J Am Coll Nutr. 2010, 29:198-203.

109. Spiller GA, Jenkins DA, Bosello O, Gates JE, Cragen LN, Bruce B: Nuts and plasma lipids: An almond-based diet lowers LDL-C while preserving HDL-C. J Am Coll Nutr. 1998, 17:285-90.

110. American Chemical Society: Walnuts are top nut for heart-healthy antioxidants . Science Daily. 2011, Accessed: October 25, 2013: http://www.sciencedaily.com/releases/2011/03/110327191040.htm.

111. Revised International Table of Glycemic Index (GI) and Glycemic Load (GL) Values . (2008). Accessed: October 25, 2013: http://www.mendosa.com/gilists.htm.

112. Dietary reference intakes tables and application. Accessed: October 25, 2013: http://www.iom.edu/Activities/Nutrition/SummaryDRIs/DRI-Tables.aspx.

113. Han X, Li J, Brasky TM, et al.: Antioxidant intake and pancreatic cancer risk: The Vitamins and Lifestyle (VITAL) Study. Cancer. 2013, 119:1314-20. 10.1002/cncr.27936

114. Dolara P, Bigagli E, Collins A: Antioxidant vitamins and mineral supplementation, life span expansion and cancer incidence: A critical commentary. Eur J Nutr. 2012, 51:769-81.

115. Bassett JK, Severi G, Hodge AM, et al.: Dietary intake of B vitamins and methionine and 
prostate cancer incidence and mortality. Cancer Causes Control. 2012, 23:855-63.

10.1007/s10552-012-9954-5

116. Hankey GJ, Eikelboom JW, Yi Q, Lees KR, Chen C, Xavier D: Treatment with B vitamins and incidence of cancer in patients with previous stroke or transient ischemic attack: results of a randomized placebo-controlled trial. Stroke. 2012, 43:1572-7.

10.1161/STROKEAHA.111.641613

117. Vidal AC, Grand DJ, Williams CD, et al.: Associations between Intake of Folate, Methionine, and Vitamins B-12, B-6 and Prostate Cancer Risk in American Veterans. J Cancer Epidemiol. 2012, 2012:957467. 10.1155/2012/957467

118. Key TJ, Appleby PN, Masset G, et al.: Vitamins, minerals, essential fatty acids and colorectal cancer risk in the United Kingdom Dietary Cohort Consortium. Int J Cancer. 2012, 131:E320-5. 10.1002/ijc. 27386

119. Lazzeroni M, Gandini S, Puntoni M, Bonanni B, Gennari A, DeCensi, A: The science behind vitamins and natural compounds for breast cancer prevention. Getting the most prevention out of it. Breast. 2011, 20:S36-41. 10.1016/S0960-9776(11)70292-2

120. Fulan H, Changxing J, Baina WY, et al.: Retinol, vitamins A, C, and E and breast cancer risk: a meta-analysis and meta-regression. Cancer Causes Control. 2011, 22:1383-96.

10.1007/s10552-011-9811-y

121. Bassett JK, Hodge AM, English DR, et al.: Dietary intake of B vitamins and methionine and risk of lung cancer. Eur J Clin Nutr. 2012, 66:182-7. 10.1038/ejcn.2011.157

122. Heinen MM, Verhage BA, Goldbohm RA, van den Brandt PA: Intake of vegetables, fruits, carotenoids and vitamins $\mathrm{C}$ and $\mathrm{E}$ and pancreatic cancer risk in The Netherlands Cohort Study. Int J Cancer. 2012, 130:147-58. 10.1002/ijc.25989

123. Lee JE, Giovannucci E, Smith-Warner SA, Spiegelman D, Willett WC, Curhan GC: Intakes of fruits, vegetables, vitamins A, C, and E, and carotenoids and risk of renal cell cancer. Cancer Epidemiol Biomarkers Prev. 2006, 15:2445-52.

124. Fortmann SP, Burda BU, Senger CA, Lin JS, Whitlock EP: Vitamin and mineral supplements in the primary prevention of cardiovascular disease and cancer: An updated systematic evidence review for the U.S. Preventive Services Task Force. Ann Intern Med. 2013, 159:824-34.

125. Grodstein F, O’Brien J, Kang JH, et al.: Long-term multivitamin supplementation and cognitive function in men: A randomized trial. Ann Intern Med. 2013, 159:806-14.

126. Lamas GA, Boineau R, Goertz C, et al.: Oral high-dose multivitamins and minerals after myocardial infarction: A randomized trial. Ann Intern Med. 2013, 159:797-805.

127. Holick CN, De Vivo I, Feskanich D, Giovannucci E, Stampfer M, Michaud DS: Intake of fruits and vegetables, carotenoids, folate, and vitamins A, C, E and risk of bladder cancer among women (United States). Cancer Causes Control. 2005, 16:1135-45.

128. Neuhouser ML, Wassertheil-Smoller S, Thomson C, et al.: Multivitamin use and risk of cancer and cardiovascular disease in the Women's Health Initiative cohorts. Arch Intern Med. 2009, 169:294-304. 10.1001/archinternmed.2008.540

129. Mursu J, Robien K, Harnack LJ, Park K, Jacobs DR: Dietary supplements and mortality rate in older women: The Iowa Women's Health Study. Arch Intern Med. 2011, 171:1625-33. 10.1001/archinternmed.2011.445

130. Bjelakovic G, Gluud C: Vitamin and mineral supplement use in relation to all-cause mortality in the Iowa Women's Health Study. Arch Intern Med. 2011, 171:1633-4.

10.1001/archinternmed.2011.459

131. Gaziano JM, Sesso HD, Christen WG, et al.: Multivitamins in the prevention of cancer in men: the Physicians' Health Study II randomized controlled trial. JAMA. 2012, 308:1871-80.

132. Linder JA: Vitamin D and the cure for the common cold . JAMA. 2012, 308:1375-6. 10.1001/jama.2012.13130

133. Murdoch DR, Slow S, Chambers ST, et al.: Effect of vitamin D3 supplementation on upper respiratory tract infections in healthy adults: The VIDARIS randomized controlled trial. JAMA. 2012, 308:1333-9. 10.1001/jama.2012.12505

134. Douglas RM, Hemila H, Chalker E: Vitamin C for preventing and treating the common cold . Cochrane Database Syst Rev.. 2007, Jul 18:CD000980.

135. Cabanillas F: Vitamin C and cancer: what can we conclude--1,609 patients and 33 years later? . P R Health Sci J. 2010, 29:215-7.

136. Thomas LD, Elinder CG, Tiselius HG, Wolk A, Akesson A: Ascorbic acid supplements and kidney stone incidence among men: A prospective study. JAMA Intern Med. 2013, 173:386-8. 


\section{Cureus}

\subsection{1/jamainternmed.2013.2296}

137. Snodgrass SR: Vitamin neurotoxicity. Mol Neurobiol. 1992, 6:41-73.

138. Panel on Micronutrients, Food and Nutrition Board: Vitamin A. Dietary Reference Intakes for Vitamin A, Vitamin K, Arsenic, Boron, Chromium, Copper, Iodine, Iron, Manganese, Molybdenum, Nickel, Silicon, Vanadium, and Zinc. The National Academies Press, Washington, DC; 2001. 82-161.

139. Hathcock JN, Shao A, Vieth R, Heaney R: Risk assessment for vitamin D . Am J Clin Nutr. 2007, 85:6-18.

140. Sanders KM, Stuart AL, Williamson EJ, et al.: Annual high-dose oral vitamin D and falls and fractures in older women: A randomized controlled trial. JAMA. 2010, 303:1815-22. 10.1001/jama.2010.594

141. Miller ER 3rd, Pastor-Barriuso R, Dalal D, Riemersma RA, Appel LJ, Guallar E: Meta-analysis: High-dosage vitamin E supplementation may increase all-cause mortality. Ann Intern Med. 2005, 142:37-46.

142. Dietary Supplement Fact Sheet: Vitamin E . (2013). Accessed: October 25, 2013 : http://ods.od.nih.gov/factsheets/VitaminE-HealthProfessional/.

143. Xiao Q, Murphy RA, Houston DK, Harris TB, Chow WH, Park Y: Dietary and supplemental calcium intake and cardiovascular disease mortality: the National Institutes of Health-AARP diet and health study. JAMA Intern Med. 2013, 173:639-46. 10.1001/jamainternmed.2013.3283 